\title{
Predictive Factors Associated with Breastfeeding Initiation and Duration Behaviors of 6-months Postpartum Mothers Referred to Health Centers in the City of Qazvin Based on Theory of Planned Behavior
}

\begin{abstract}
Background and objective: Exclusive breastfeeding (EBF) is an important issue in the field of children's health promotion. The aim of this study was to identify the predictive factors of breastfeeding behaviors in order to improve the quality of breastfeeding among Iranian mothers.

Materials and methods: A longitudinal study was conducted to collect the data from a large sample of 1445 six-months postpartum mothers referred to health centers in the city of Qazvin, Qazvin province, Iran in 2014. Demographic variables and the constructs of Theory of Planned Behavior (TBP) were measured by a questionnaire. Use of Pearson and Spearman correlation tests along with analysis of variance were conducted to investigate potential associations. Then both hierarchal multiple regression and logistic regression were applied to identify potential determinative factors through SPSS version 21.00 .

Results: The average age of the participants was $28.6 \pm 5.5$ and the majority of maternal were housewives (75.2\%). Variables such as age, income, employment and primiparity were associated with EBF $(p<0.05)$. The constructs of TPB could significantly predict the EBF behavior, which accounts for $59 \%$ of the variance among the predicting factors. Self-identity and moral norms could increase the variance by an additional $15 \%$. Younger mothers with lower education levels and insufficient income were at higher risk of EBF cessation.

Conclusion: Interventions to promote knowledge, attitude and behavioral control towards EBF among the young mothers with low socioeconomic status should be considered.

Paper Type: Research Article.

Keywords: Breastfeeding behavior, Exclusive breastfeeding (EBF), Theory of Planned Behavior (TPB), Breastfeeding predictive factors, Iranian mothers, Qazvin.

Citation: Pakpour A., Alijanzadeh M., Pouresmaeil M., Taherkhani F., Mohammadgholiha R., Jozi N. Predictive Factors Associated with Breastfeeding Initiation and Duration Behaviors of 6-months Postpartum Mothers Referred to Health Centers in the City of Qazvin Based on Theory of Planned Behavior. Iran $J$ Health Educ Health Promot. Spring 2016;4(1):20-30.
\end{abstract}

Amir Pakpour

*Assistant Professor in Health Education, Social Determinants of Health Research Center, Qazvin University of Medical Sciences (QUMS), Qazvin, Iran (Corresponding author) Tel: 02833239259 Pakpour_amir@yahoo. com

Mehran Alijanzadeh

Ph.D. Candidate in Health Care Management, Social Determinants of Health Research Center, QUMS, Qazvin, Iran

Mahnaz Pouresmaeil

MSc in Health Education, Social Determinants of Health Research Center, QUMS, Qazvin, Iran

Fahimeh Taherkhani

BSc in Public Health, Social Determinants of Health Research Center, QUMS, Qazvin, Iran

Rana Mohammadgholiha

BSc in Public Health, Social Determinants of Health Research Center, QUMS, Qazvin, Iran

Narges Jozi

BSc in Public Health, Social Determinants of Health Research Center, QUMS, Qazvin, Iran

Received: 13 JaNuary 2016 Accepted: 09 April 2016 


\section{عوامل بيشعويى كننله آغاز و تفاوم رفتار شيردهى در مادران داراى كودى 9 ماهه مراجعه كننله به مراكز بهداشتى درماذى شهر قزوين بر اساس الثَوى رفتار برنامهريزىشله}

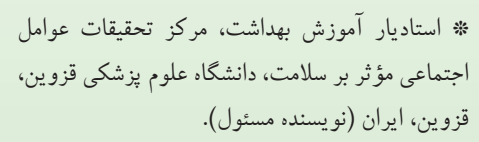

مهر ان عليجانزاده دانشجوى دكترى تخصصى مديريت بهداشت و درمان،

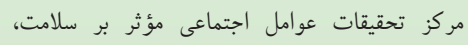
دانشكاه علوم يزشكى قزوين، قزوين، ايران مهناز بوراسماعيل كارشناسىارشد آموزش بهداشت، مركز تحقيقات

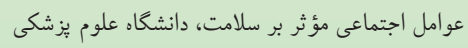
قزوين، قزوين، ايران

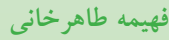
كارشناسى بهداشت عمومى، مركز تحقيقات عوامل

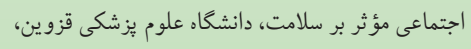
قزوين، ايران رعنا محمدقليها

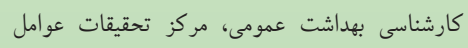

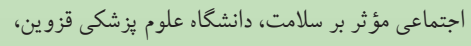
قزوين، ايران

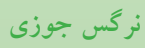

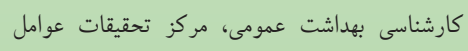

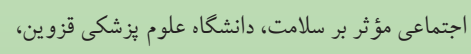
قزوين، ايران

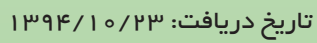

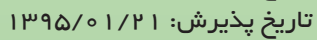

\section{ه}

زمينه و هدف :تغذيه انحصارى با شير مادر موضوعى مهرم در زمينه ارتقا سلامت كودكان است. هدف

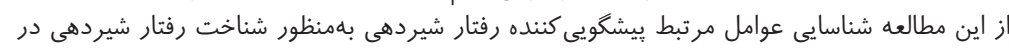
مادران ايرانى بود.

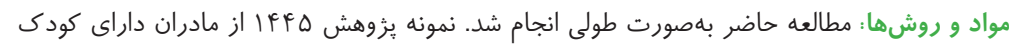

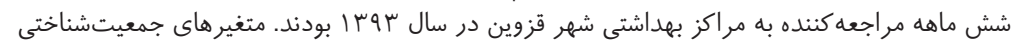

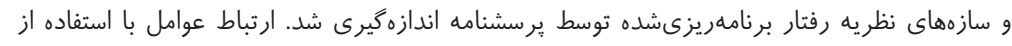

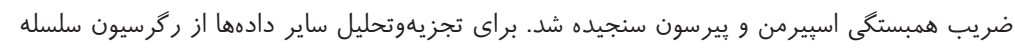

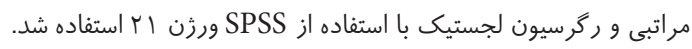

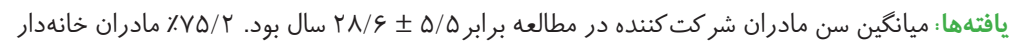

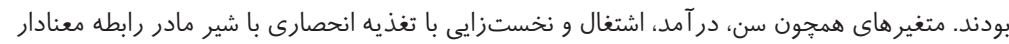

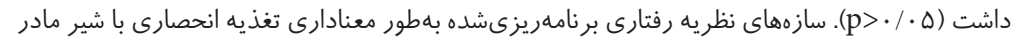

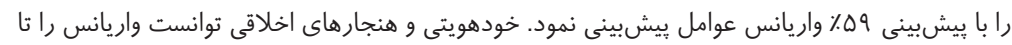

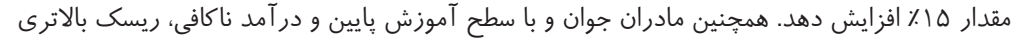

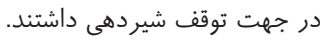

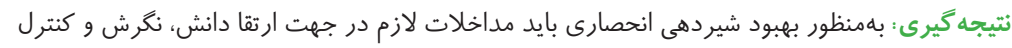

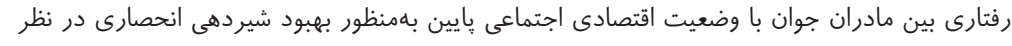

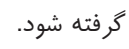

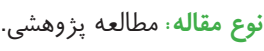

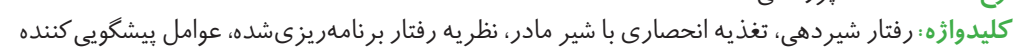
شيردهى، مادران ايرانى، قزوين.

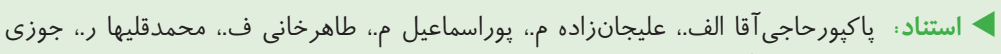

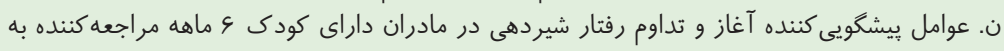

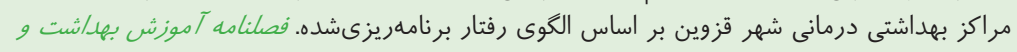

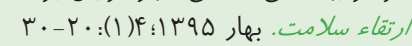




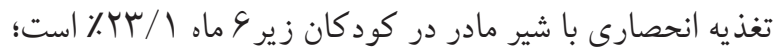
كه اين ميزان در استان قزوين

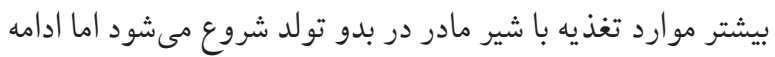

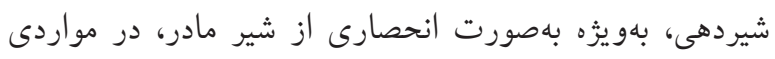
ناديده گرفته مى شود (11). در اين زمينه، شناسايى عو امل مؤثر

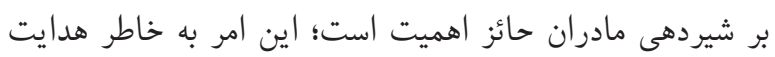
برنامههاى ترويج تغذيه شير مادر با تمر كز بر اين عوامل در جهت

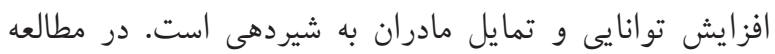

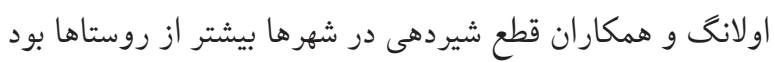

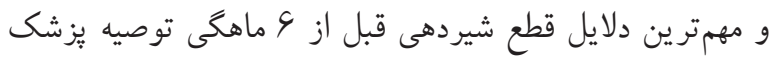
(OFF)

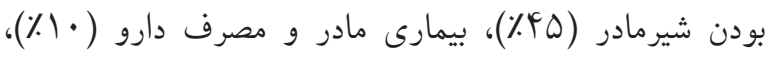

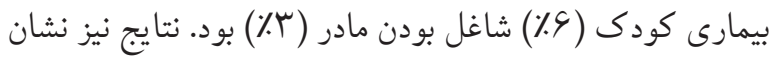

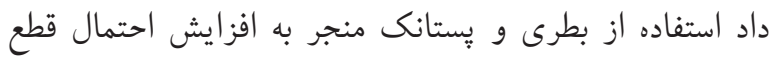

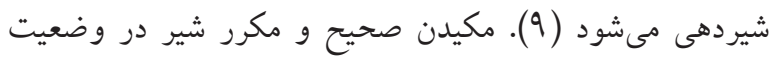

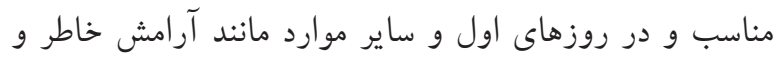

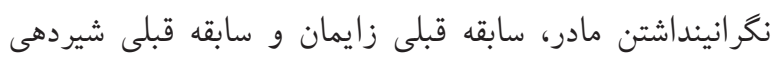
موفق، حمايت همسر و افراد خانواده و نيز اطمينان خاطر از تأمين اقتصادى و شغلى مى تواند نقش مؤثرى در تداوم شيردهى داشته

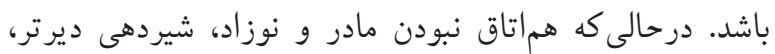
شروع نكردن بهموقع تغذيه تكميلى، ترخيص نشدن همزمان مادر

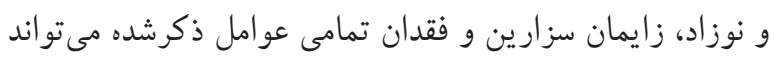

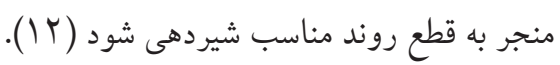

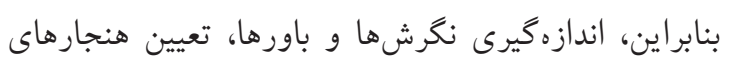

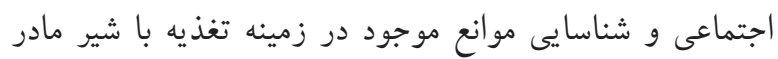

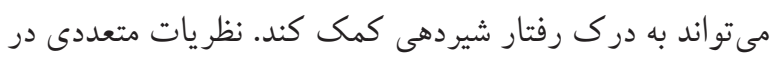
مورد نقش باورها و عقايد جمعيتها در مورد انجام رفتارهاى دمري

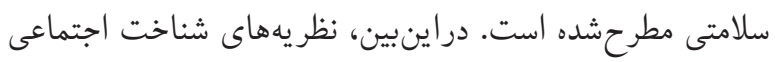
جهارجوب خوبى براى فهم رفتارهاى سلامتى ارائه مى دهند(

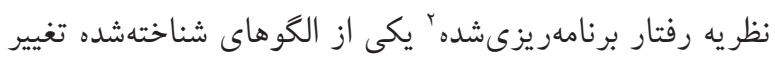

امروزه، توجه ملى بر اين نكته معطوف شده است كه سالهاى اوليه

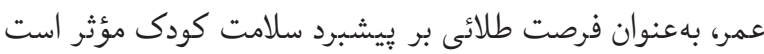

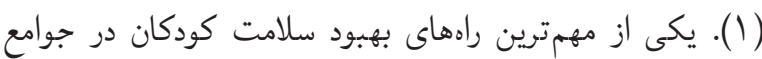
مختلف شيردهى است. مطابق با يافتهاى يونيسف بيش از سه هزار كودى هرروزه از بيمارىهاى عفونى به علت تغذيه با بطرى

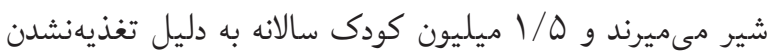
با شير مادر به سمت مرگ سوق بيدا ميى كنند (Y). در اواخر دهه 1999، مادران نسبت به مزاياى شير مادر آكاهى بيشترى يافته

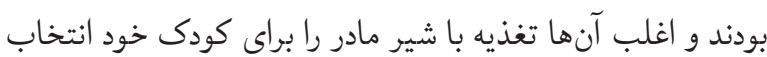

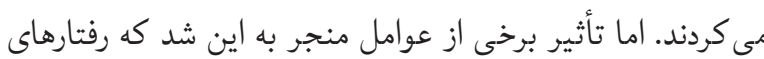

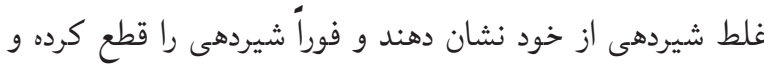
تغذيه كمكى را براى كودى خود آغاز كنند؛ اين امر صدمات وندات

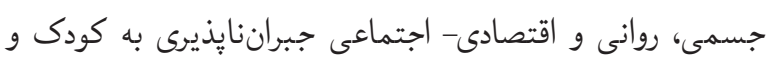
درنهايت جامعه وارد مى كند (广). شيرمادر، تغذيهاى مطلوب براى رشد و تكامل كود كان است؛

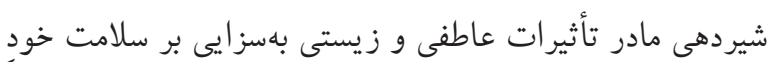

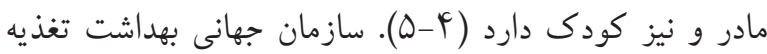
انحصارى با شير مادر را تا سن 9 ماهكى براى كودكان توصيه

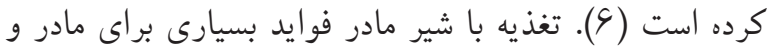

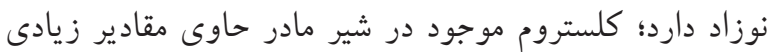

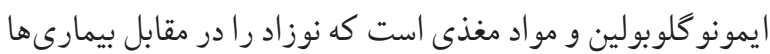
ازجمله بيمارىهاى عفونى مانند بيمارىهاى اسهالى، ذاتالريه و

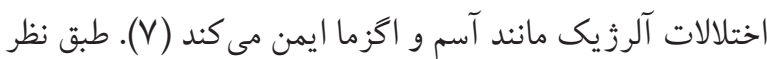
سازمان جهانى بهداشت، شروع تغذيه با شير مادر در ساعت اول

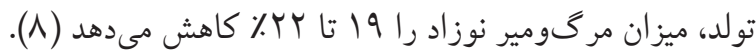

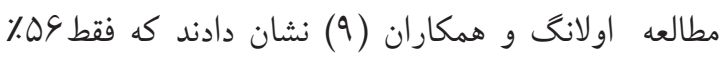

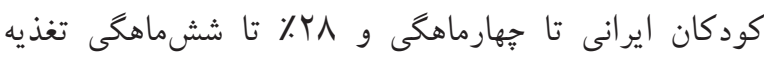
انحصارى با شير مادر داشتند؛ اين ميزان كمتر از ميزان بيشنهادى

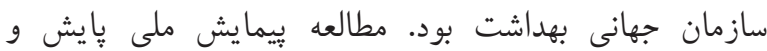

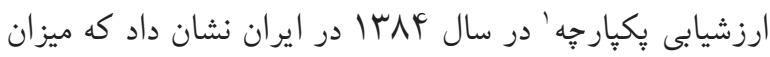
1. National Integrated Monitoring and Evaluation Survey (IMES) 
اساس نتايج اين يُوهش تا با نتايج حاصل از آن، بتوان عوامل مؤثر بر حفظ و تداوم شيردهى مادران را مشخص كرد و اين

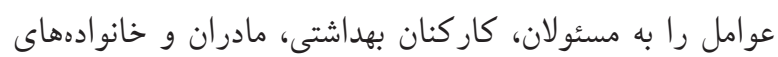
آنان معرفى كرد.

مو ادو و روشها

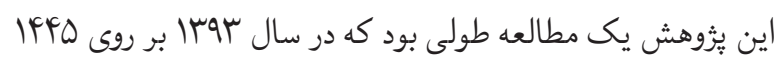

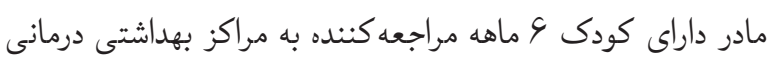

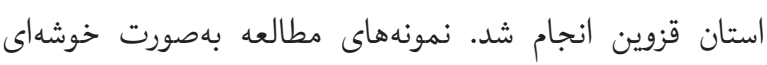

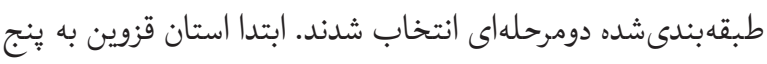

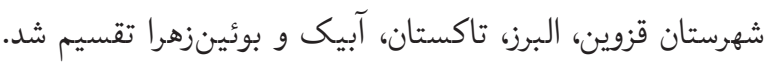
سبيس مركز بهداشت هر شهرستان بهعنوان طبقات انتخاب و وتمام مراكز شهرى-روستايى بهعنوان خوشه در نظر كرفته شدند. نمونها

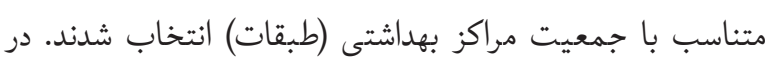

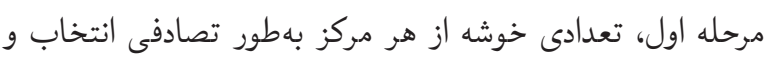

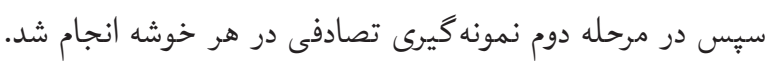

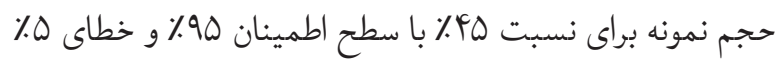

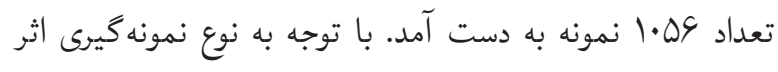

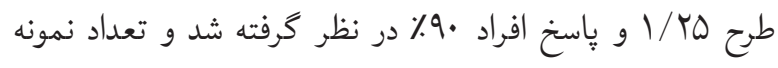

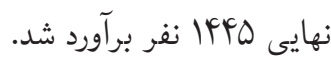

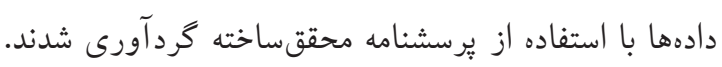
اين يرسشنامه داراى هفت بخش بود. بخش اول، سؤالات

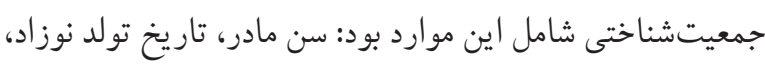

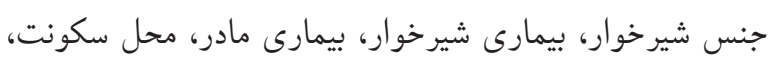

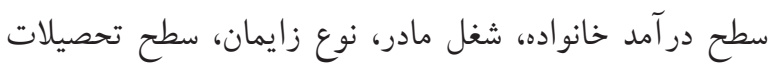

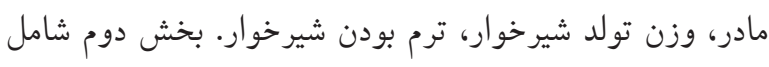

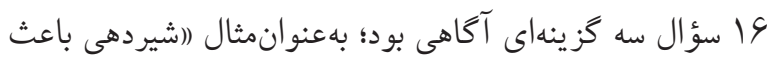

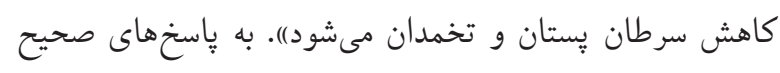

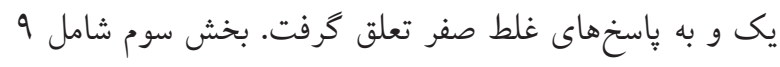

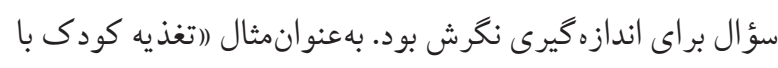

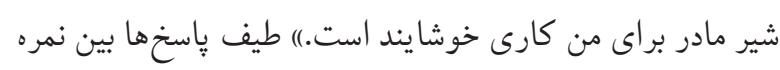

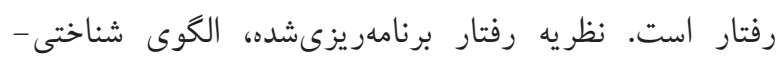

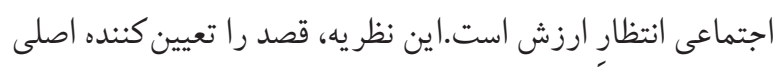

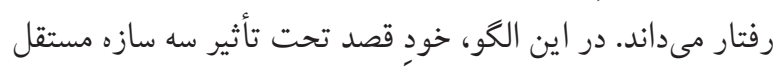

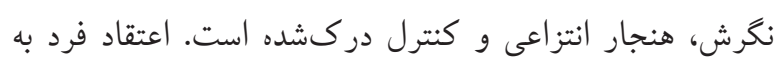

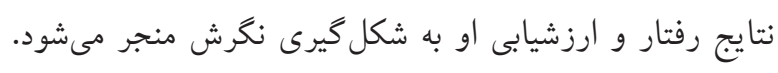
بعضى اعتقادات رفتارى از تجارب مستقيم خود فرد سرجشيمه

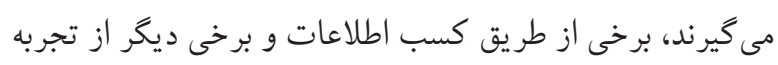

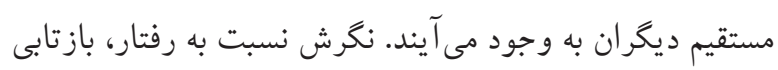

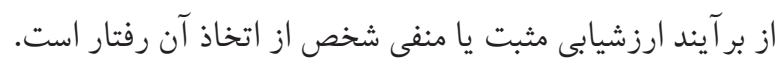

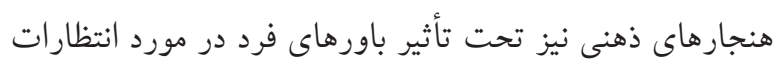

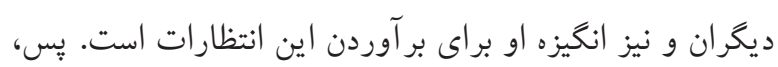

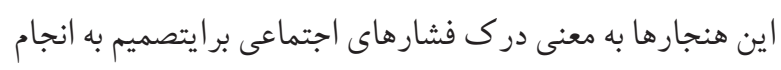
دادن يا انجام ندادن رفتار است. باورهاى هنجارى بهصورت إنائ

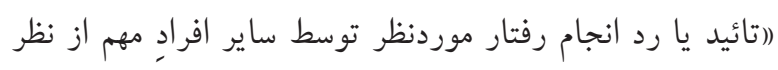

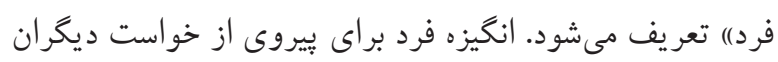

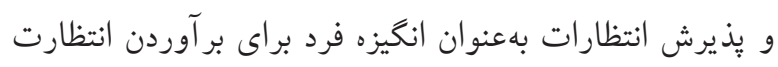

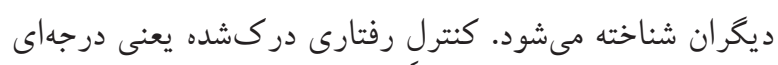

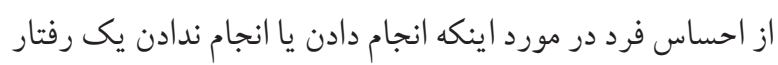

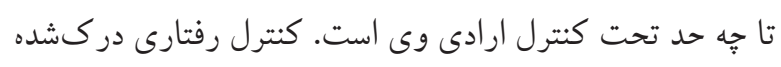

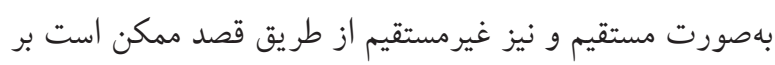

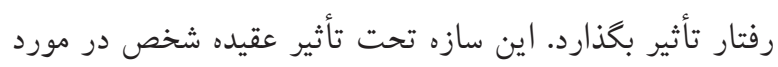

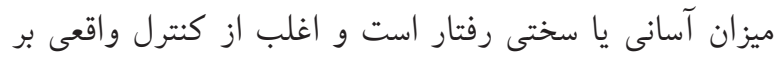
رفتار نشأت مى كيرد.

به دليل اهميت تغذيه با شير مادر و لزوم شناسايى عوامل

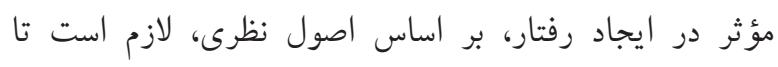

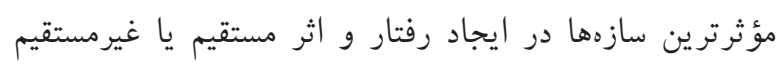

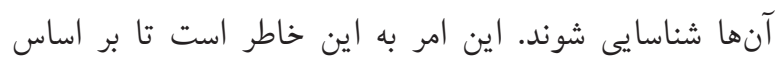

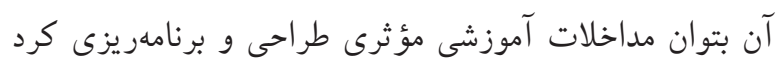

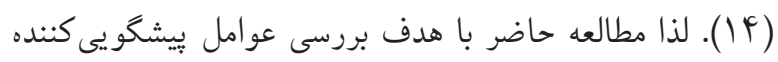

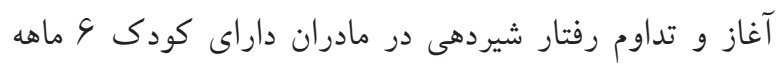

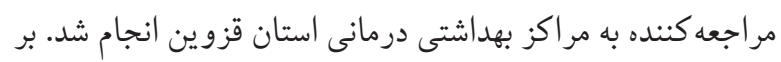


بيشبينى كنند گى كنترل رفتارى متصور، قصد، برنامهريزى براى

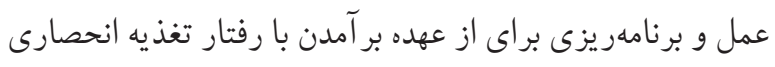

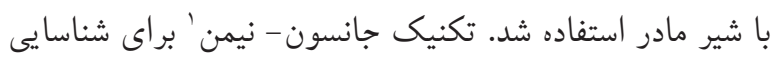
محدوده در دامنه متغيرهاى ميانجى (قصد) بكار رفت.

يافنه ها

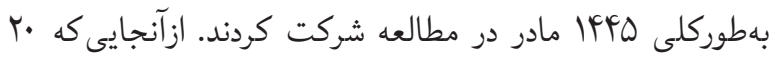

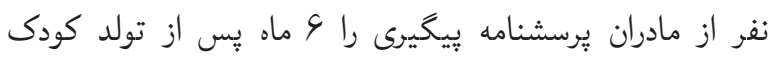

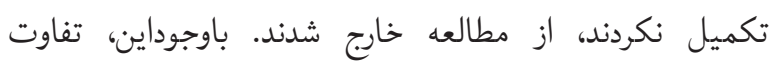

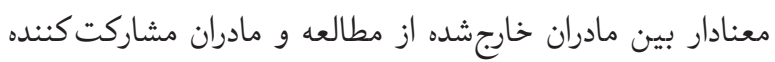

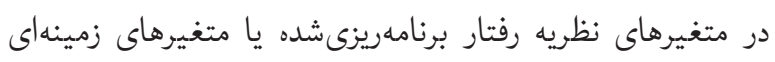

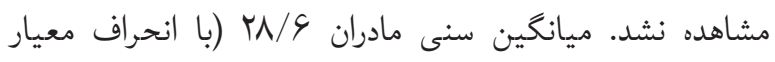

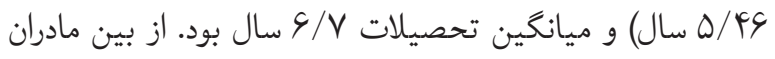

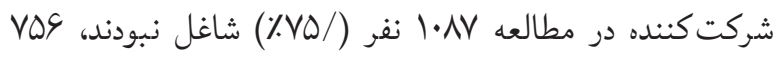

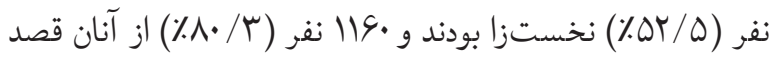

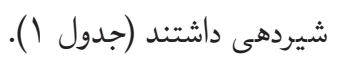

جدول ا. فراوانى و ميانگين سازههاى مدل رفتار برنامهريزىشده و متغير هاى جمعيتشناختى مادران داراى كودى و ماهه مراجعه كننده

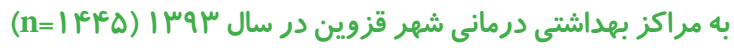

\begin{tabular}{|c|c|}
\hline فراوانى و ميانغين & متغير ها \\
\hline$r N / \Delta q \pm \Delta / \uparrow q$ & سن (ميانگين 土 انحراف معيار) \\
\hline$\varphi / V \cdot \pm r / \varphi q$ & سالهاى تحصيل \\
\hline$q 1 \Lambda / 4 q \pm \Delta q \vee / \mu s$ & در آمد خانوار ( . . ا ريال) \\
\hline 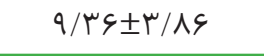 & آكاهى \\
\hline$F / I V \pm 1 / \mu r$ & 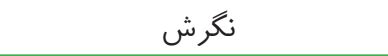 \\
\hline D & هنجار هاى انتزاعى \\
\hline$r / r \mu \pm 1 / \mu 1$ & كنترل رفتارى دركشده \\
\hline$r / 19 \pm 1 / 19$ & قصد رفتارى \\
\hline$r / r \Delta \pm I / F r$ & هنجارهاى اخلاقى \\
\hline$r / r \wedge \pm 1 / 19$ & خود هويتى \\
\hline
\end{tabular}

1. Johnson-Neyman technique
ينج (مطلوب ترين ياسخ) و صفر بود. در بخش جهارم از سه سؤال

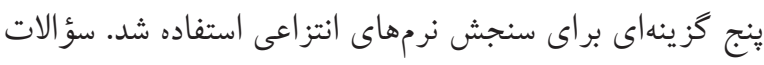

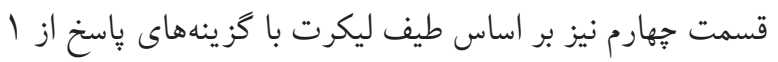

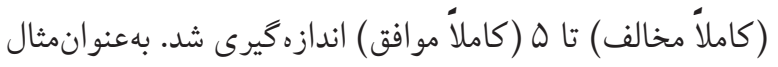

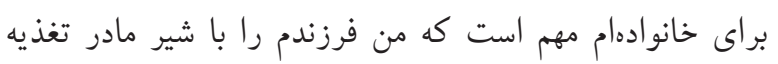

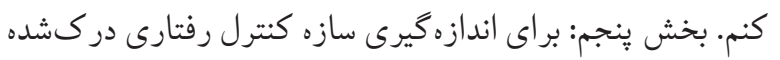

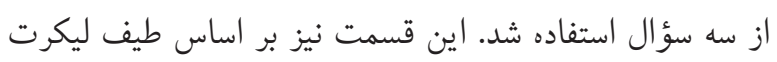

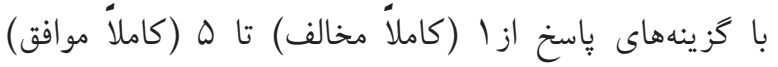

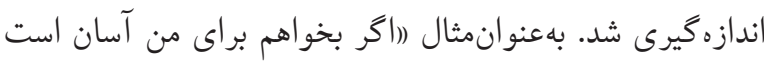

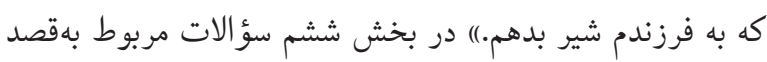

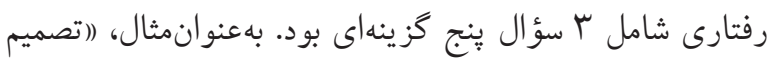

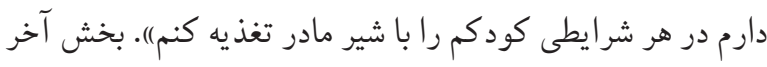

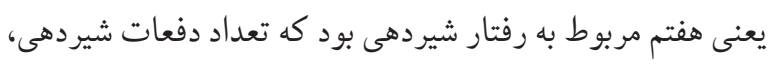
مدتزمان شيردهى، علت قطع شيردهى، ادامه تغذيه با شيرمادر يس از شروع تغذيه كمكى را مورد ارزيابى قرارداد.

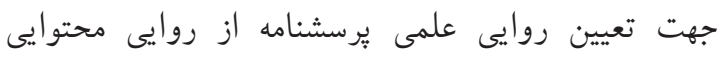

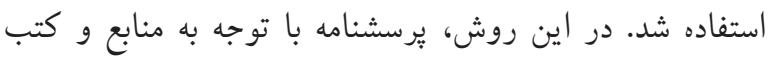

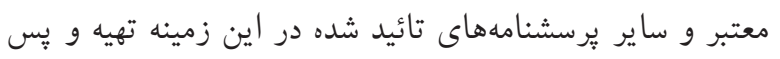

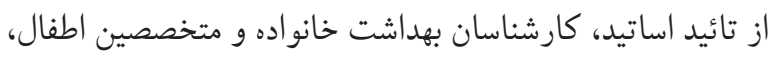

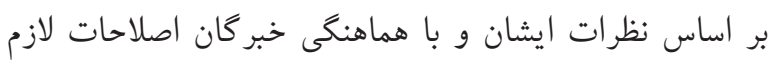

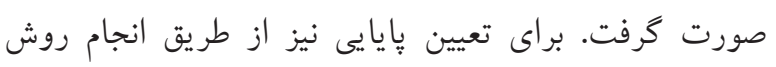

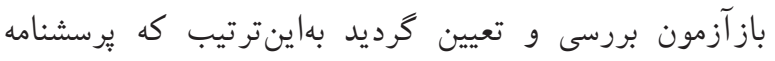

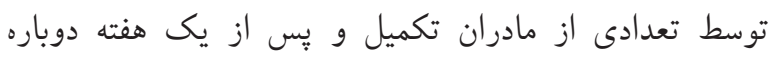

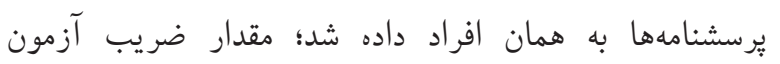
باز آزمون برابر با 94٪ بوده. دادهها با استفاده از نرمافزار

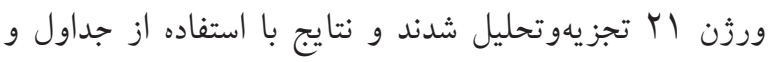

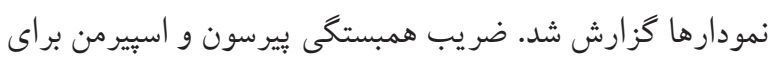
شناسايى متغيرهاى جمعيتشناختى و شناسايى رابطه معنادار متغيرهاى جمعيتشناختى با رفتار شيردهى بكار رفت. آزمون تى زوجى براى بررسى اثرات متغيرهاى كنترل بالقوه استفاده شد.

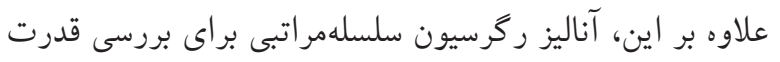


شيردهى داشتند. آنها اهميت فشار اجتماعى را براى شيردهى به نوزادان درك كرده و ادعا مىكردند كه شيردهى خود را تحت كنترل دارند. آزمون همبستخى ارتباط معنادارى بين سن، وردي،

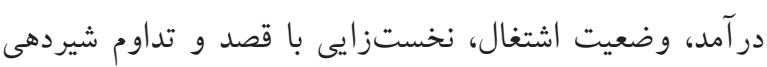

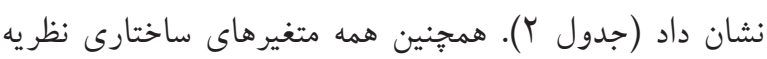

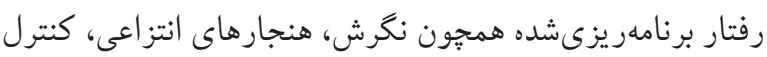
رفتارى دركشده و قصد، خودهويتى و هنجارهاى اخلاقى با

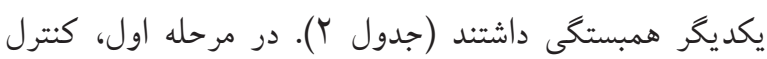

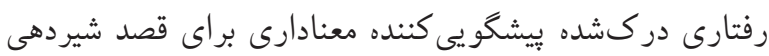

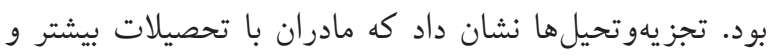

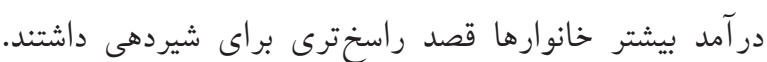

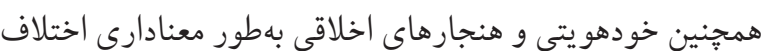

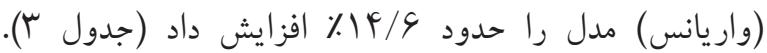

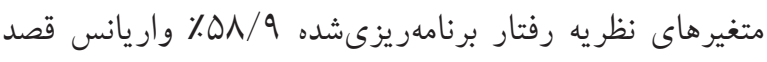
شيردهى را بيش بينى مى كردند.

\begin{tabular}{|c|c|}
\hline تعداد (٪) & \\
\hline $\begin{array}{l}(\% \Delta 1 / \cdot) \vee \mu r \\
(\% \varphi q / \cdot) \vee \cdot \wedge\end{array}$ & جنس كود \\
\hline $\begin{array}{l}(\% \Delta Y / \Delta) \vee \Delta \Lambda \\
(\% Y V / \Delta) \text { SAV }\end{array}$ & فرزند اول \\
\hline $\begin{array}{l}(\% r F / \Lambda) \Gamma \Delta q \\
(\% \vee \Delta / r) \mid \cdot \wedge \varsigma\end{array}$ & خانهيت اشتغال \\
\hline $\begin{array}{l}(\% \mu F / r) F q F \\
(\% 9 \Delta / \Lambda) 901\end{array}$ & نوع زايمان \\
\hline 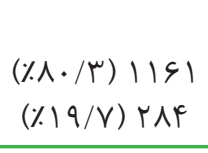 & تغذيه با شير مادر هنغام تولد \\
\hline $\begin{array}{l}(\% \mu F / q) \& q . \\
(\% q \Delta / q) q \mu \Delta\end{array}$ & تغذيه با شير مادر در 9 ماهه اول تولد \\
\hline
\end{tabular}

بيشتر مادران شاغل در اين مطالعه نكرش مثبت و قصد

جدول r. جدول همبستكى متقابل متغيرهاى زمينهاى و ساختارى داراى كودى \& ماهه مراجعه كننده به مراكز بهداشتى درمانى شهر قزوين در سال سوس | (n) (

\begin{tabular}{|c|c|c|c|c|c|c|c|c|c|c|c|c|c|c|}
\hline 10 & If & Ir & ir & 11 & 1. & 9 & $\wedge$ & $v$ & \& & $\Delta$ & f & $\mu$ & r & \\
\hline .1 .4 &.$/ 14^{*}$ & .1 .0 & $\cdot / \cdot v$ & $.110^{* * * * *}$ & $\cdot / \cdot \wedge$ & .1 .4 & $\cdot / \cdot 1$ & $\cdot / 1$. & .1 .0 & 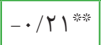 &.$/ 1 \mu^{*}$ &.- .1 .9 & .1 .9 & ا \\
\hline.$/ .0$ &.$/ .0$ &.$- / \cdot r$ &.$/ \cdot f$ & .1 .0 &.$/ \cdot r$ & $\cdot / \cdot r$ &.$/ \cdot q$ &.$/ .1$ & .1 .9 &.$/ \cdot r$ & $\cdot / \cdot \mu$ & $\cdot / \cdot \Lambda$ & & r. جنس كودك+ \\
\hline$\cdot / \cdot \Lambda$ & 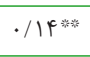 &.$/ \cdot r$ &.$/ 14$ & $\cdot / 19^{* * * * * *}$ &.$/ .4$ & $\cdot / \cdot \mathrm{V}$ & $\cdot / \cdot \Lambda$ &.$/ 1 r^{*}$ & 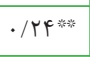 &.$/ \cdot r$ & 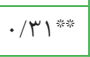 & & & بـ وضعيت اشتغال + \\
\hline$\cdot / \cdot \mathrm{V}$ &.$/ 11$ 粬 &.$/ 1$ &.$/ \cdot r$ & .1 .0 & $\cdot / \cdot V$ & .1 .0 &.$/ \cdot r$ &.$/ \cdot r$ & 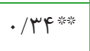 &.$/ \cdot r$ & & & & F F. درامد \\
\hline ・八. 䍶 & 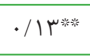 & $\cdot / \cdot r$ & $\cdot / \cdot r$ &.$/ \cdot 9^{*}$ & $\cdot / \cdot \vee$ &.$/ .0$ & .1 .4 & $\cdot / \cdot \Lambda$ &.$/ 11 \%$ & & & & & ه. فرزند نخست+ \\
\hline.$/ .9 \%$ &.$/ 19$ 乘 & $\cdot / \cdot 1$ &.$/ .0$ & $\cdot / 11$ 柲 &.$/ .9 *$ & $\cdot / 1 \cdot *$ &.$/ .9^{*}$ &.$/ 1 r^{* * *}$ & & & & & & 9. تحصيلات \\
\hline$\cdot / r Y^{* * * * * * a *}$ & $\cdot / \Upsilon^{*}{ }^{* * * * *}$ & $\cdot / r \Lambda^{* * * * ⿲ 二 丨 匕}$ & 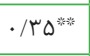 & 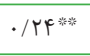 & $\cdot / r \cdot *$ & 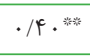 & $\cdot / \Gamma^{*}$ & & & & & & & 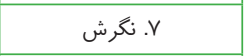 \\
\hline$\cdot / r \Lambda^{* * a}$ & $\cdot / Y^{* * *}$ & $\cdot / \gamma^{* * * *}$ & $\cdot / 19^{* * * * *}$ & $\cdot / \Upsilon^{*}$ &.$/ q^{* * * * *}$ & $\cdot / \Gamma \Delta^{*}$ & & & & & & & & ــــ هنجار هاى انتزاعى \\
\hline 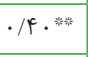 & $\cdot / 19^{* * * * *}$ & 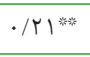 & 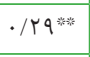 & $\cdot / \mu \mu^{* * * * * 0}$ & $\cdot / q^{*}$ & & & & & & & & & 9. كنترل رفتارى درك شده \\
\hline 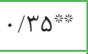 & $\cdot / 19^{* * \% *}$ & 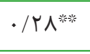 & 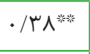 & 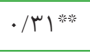 & & & & & & & & & & • ا. قصد رفتارى \\
\hline$\cdot / \uparrow \Delta^{* * * *}$ & $\cdot / \mu \cdot w_{*}^{* * * *}$ & $\cdot / \tau ץ^{*}$ & $\cdot /\left.r\right|^{\prime * * * a n}$ & & & & & & & & & & & 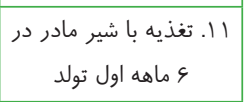 \\
\hline$\cdot / \uparrow \theta^{* * * \ldots=0}$ & $\cdot / 19^{* * * * *}$ & $\cdot / \mathscr{F} V^{* * * * *}$ & & & & & & & & & & & & r ا. خود هويتى \\
\hline 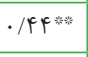 & $\cdot / \mu^{\mu \ldots * \ldots *}$ & & & & & & & & & & & & & سَّ ا. هنجارهاى اخلاقى \\
\hline 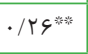 & & & & & & & & & & & & & & 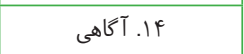 \\
\hline & & & & & & & & & & & & & & 10 ا. تغذيه با شير مادر \\
\hline
\end{tabular}




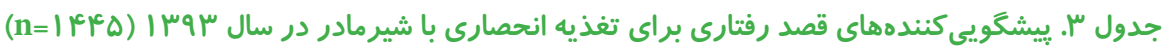

\begin{tabular}{|c|c|c|c|c|c|c|}
\hline \multicolumn{2}{|c|}{$\mathrm{CI} \% 9 \diamond$} & \multirow{2}{*}{ انحر اف } & \multirow{2}{*}{ تغييرات } & \multirow{2}{*}{$\begin{array}{c}\text { تغيير ات } \\
\text { rR }\end{array}$} & \multirow[b]{2}{*}{$\beta$} & \\
\hline بالاترين & يايينترين & & & & & \\
\hline & & & 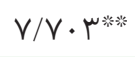 & $\cdot / p q p$ & & كام اول t \\
\hline \multirow{3}{*}{$\cdot / \cdot V G$} & $\cdot|\cdot|+1$ & 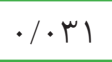 & & & $\cdot / \cdot r \cdot$ & سن \\
\hline & & & & & & فرزند نخست \\
\hline & & & & & & خير \\
\hline$\cdot / r \cdot c$ & $-\cdot / I r F$ & $\cdot / \cdot \Lambda F$ & & & $\cdot / \cdot p_{1}$ & بله \\
\hline \multirow{3}{*}{.$/ 19 \mathrm{~V}$} & • / r r & $\cdot / \cdot V \cdot$ & & & $\cdot / 1 \ldots$ **** & تحصيلات \\
\hline & & & & & & وضعيت اشتغال \\
\hline & & & & & & خانهدار \\
\hline$\cdot / r V V$ & $-\cdot / r F$ & $\cdot / \cdot F G$ & & &.$/ .9 V$ & شاغل \\
\hline.$/ 199$ &.$/ \cdot 4 q$ & •/. I I & & & $\cdot / 1 \cdot 9 * * *$ & درامد خانوار \\
\hline$\cdot / r \cdot V$ & $\cdot / \cdot V^{\mu}$ & $\cdot / \cdot r p$ & & & $\cdot / 1 \mathrm{f}$. *** & آكاهى \\
\hline ( &.$/ \cdot 94$ & ./.rs & & & $\cdot / 190^{*}{ }^{*}$ & 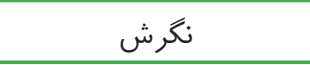 \\
\hline$\cdot /$ rqه & $\cdot / Y F A$ & $\cdot / \cdot r V$ & & & . & هنجارهاى انتزاعى \\
\hline \multirow{2}{*}{$\cdot / \Delta ૬ \Delta$} & $\cdot / 4 r q$ & $\cdot / \cdot r \Delta$ & & & $\cdot / \uparrow q V^{* * * *}$ & كنترل رفتارى درك شده \\
\hline & & & 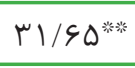 &.$/ 144$ & & كام دوم t ك \\
\hline \multirow[t]{3}{*}{$\cdot / \cdot \wedge$} & $-\cdot / \cdot r p$ & $\cdot / \cdot r \cdot$ & & & ( & سن \\
\hline & & & & & & فرزند نخست \\
\hline & & & & & & خير \\
\hline$\cdot / \cdot \vee r$ & $-\cdot / \cdot f r$ & $\cdot / \cdot r q$ & & & $.1 \cdot 10$ & بله \\
\hline \multirow[t]{3}{*}{.$/ 189$} & $\cdot / \cdot F V$ & سץ./. & & & $\cdot / 111^{\text {粠米 }}$ & تحصيلات \\
\hline & & & & & & وضعيت اشتعال \\
\hline & & & & & & خانهدار \\
\hline$\cdot / \cdot r \wedge$ & $-\cdot / 1 \Delta r$ & $\cdot / \cdot i c$ & & &.$/ .9 r$ & 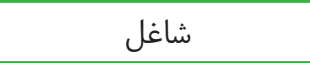 \\
\hline$\cdot / r \& q$ &.$/ \cdot g q$ & $\cdot / \cdot \Delta r$ & & & $\cdot / 19 V^{*}$ & درامد خانوار \\
\hline$\cdot / 1 V$ & . & $\cdot / \cdot r \mu$ & & & $\cdot / 1 \cdot r^{\text {世釉粰 }}$ & آ آكاهى \\
\hline.$/ 1 \mathrm{~V} \Delta$ & $\cdot / \cdot \mathrm{rA}$ & $\cdot / \cdot r V$ & & & $\cdot / 1 \cdot r^{\text {米䅴 }}$ & 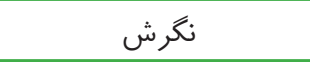 \\
\hline 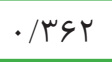 & $\cdot / Y \mid S$ & $\cdot / \cdot$ щ人 & & & $\cdot / r \wedge 9^{*} * * * *$ & هنجارهاى انتزاعى \\
\hline 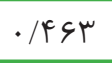 & $\cdot / \mu \cdot \Delta$ & $\cdot / \cdot p$ & & & 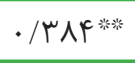 & كنترل رفتارى درك شده \\
\hline.$/ 499$ & ( & $\cdot / \cdot q \mu$ & & & 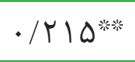 & خود هويتى \\
\hline.$/$ IfF & $.1 \cdot 1$ & $\cdot / \cdot r \mu$ & & & $\cdot / \cdot V V^{\text {***** }}$ & هنجارهاى اخلاقى \\
\hline
\end{tabular}


در مرحله اول، احتمال تداوم رفتار شيردهى در مادران غير به شيردهى را يبشبينى مى كرد. همجنين نتايج نشان داد توان يان

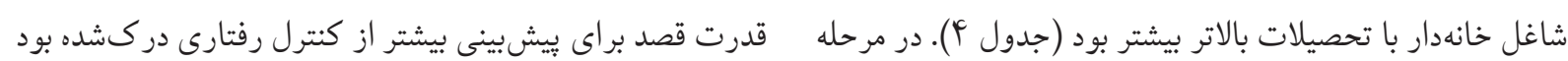

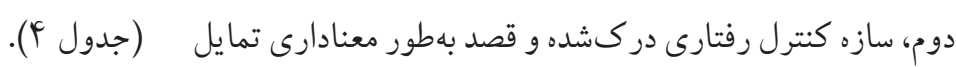

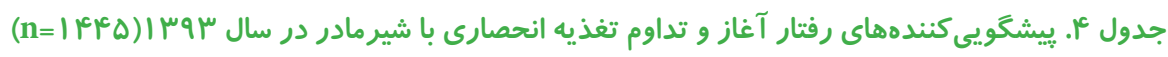

\begin{tabular}{|c|c|c|c|c|c|c|c|c|}
\hline \multicolumn{8}{|c|}{ تغذيه با شير مادر } & \multirow{4}{*}{ متغير t كام اول } \\
\hline \multicolumn{4}{|c|}{ 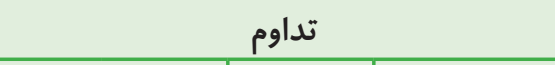 } & \multicolumn{4}{|c|}{ شروع } & \\
\hline \multicolumn{2}{|c|}{$C I \% 9 \Delta$} & \multirow[t]{2}{*}{ OR } & \multirow[t]{2}{*}{$\beta$} & \multicolumn{2}{|c|}{ CI $\% 9 \Delta$} & \multirow[t]{2}{*}{ OR } & \multirow[t]{2}{*}{$\beta$} & \\
\hline & & & & & & & & \\
\hline \multirow{3}{*}{$1 / \cdot 1$} &.$/ 909$ &.$/ 91 \mathrm{~F}$ & $-\cdot / \cdot 19$ & $1 / \cdot 1 r$ &.$/ 94$ &.$/ 919$ & $-\cdot / \cdot 14$ & سن \\
\hline & & & & & & & & فرزند نخست \\
\hline & & & & & & & & خير \\
\hline I/マ9০ & $1 / \cdot 11$ & l/FFV & $\cdot / r q \Lambda^{* * *}$ & I/AIV &.$/ 99 \mathrm{~V}$ & I/TFG & $\cdot / r q \vee$ & بله \\
\hline \multirow[t]{3}{*}{$1 / 109$} & $1 / \cdot V G$ & $1 / 110$ & 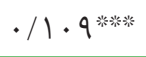 & $1 / 194$ & $1 / \cdot \wedge 1$ & $|/| r \mid$ & 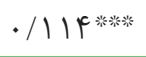 & تحصيلات \\
\hline & & & & & & & & وضعيت اشتغال \\
\hline & & & & & & & & 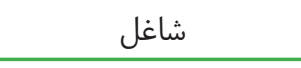 \\
\hline r/AGr & $1 / r 91$ & I/9r & 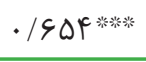 & $r / \mu \cdot f$ & $1 / 0 \cdot 9$ & سMr/r & 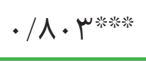 & خانهدار \\
\hline \multirow[t]{2}{*}{$1 / \cdot r F$} & .1909 &.$/ 991$ & .1 .9 & $1 / \cdot 11$ &.$/ 940$ &.$/ 9 \mathrm{VV}$ & מ & درامد خانوار \\
\hline & & & & & & & & كام دوم t كام \\
\hline \multirow[t]{3}{*}{$1 / \cdot 11$} &.$/ 941$ & $\cdot / 9 \wedge 6$ & $-\cdot / \cdot 1 \mathrm{~F}$ & سו & $\cdot / 0 \vee q$ &.$/ 910$ & $-\cdot 1 \cdot 10$ & سن \\
\hline & & & & & & & & فرزند نخست \\
\hline & & & & & & & & خير \\
\hline $1 / \Lambda \cdot V$ & $1 / \cdots r$ & l/rev & $\cdot / r q \wedge *$ & I/Ar. &.$/ 99$ & $|/ r r|$ & $\cdot / r \vee q$ & بله \\
\hline \multirow[t]{3}{*}{$1 / 190$} & س & 1/1.r & 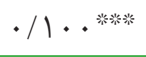 & l/Irp & $1 / \mathcal{F} V$ & $1 / \cdot 9$ & $\cdot / \cdot \wedge \varsigma^{* * * *}$ & تحصيلات \\
\hline & & & & & & & & وضعيت اشتغال \\
\hline & & & & & & & & 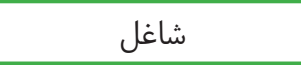 \\
\hline$r / \Delta r q$ & 1/11 & $1 / 9 \wedge 1$ & $\cdot / \Delta r \cdot *$ & $r / r F$. & I/rVr & $r / 1 \cdot q$ & 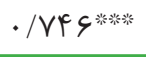 & خانهدار \\
\hline $1 / \cdot r V$ &.$/ 94$. &.$/ 994$ & 的 & l/Mp & 1/.r. & $1 / \cdot 11$ & $\cdot / \cdot V \Lambda^{* * *}$ & درامد خانوار \\
\hline$r / 4 q \nabla$ & $r / \cdot r \wedge$ & r/צ૬r & 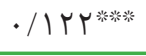 & $r / f \wedge F$ & r/r人r & r/ANI & 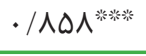 & قصد \\
\hline I/rm & $1 / \cdot r c$ & $1 / 1 \mu$ & 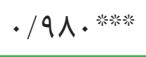 & I/rq1 & $1 / 1 \Delta \wedge$ & I/rVY & $\cdot /\left.Y F\right|^{\text {米米粠 }}$ & كنترل رفتارى درى شده \\
\hline
\end{tabular}

به مراكز بهداشتى درمانى استان قزوين بود. نتايج مطالعه نشان بحث

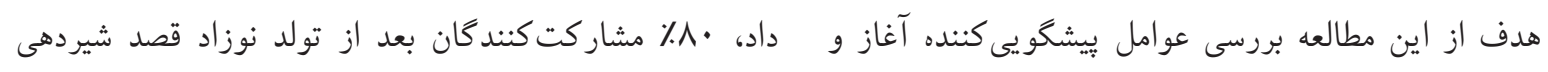

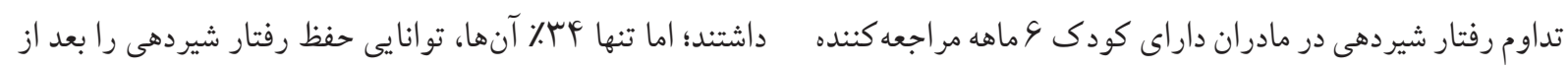


نقش مؤثرى در بيشبينى رفتارهاى شيردهى مادران براى 9

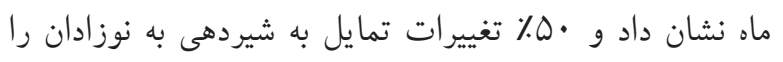

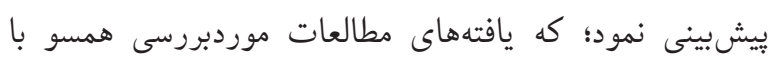
مطالعه حاضر بود. هوى و آبراهامز (Yצ) بيان مى كنند، هنگامى كه رفتارى

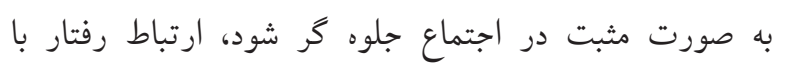
قصد انجام اين عمل بسيار محتملتر است. بر طبق نتايج اين مطالعه، هنجارهاى اخلاقى اثر خود را بر رفتار شيردهى نشان بنان داد؛ بهطورى كه منجر به كاهش شكاف بين قصد و انجام رفتار شيردهى شد. نتايج استفاده از اين الكوهاى جديد در نظريه رفتنار

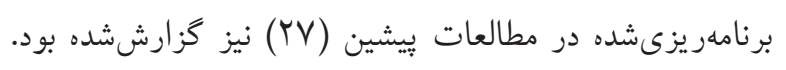
طبق نتايج مطالعه حاضر عوامل سن، وضعيت اقتصادى و اشتغال با قصد شيردهى ارتباط داشت. همجنين آموزش و در آمد بهعنوان

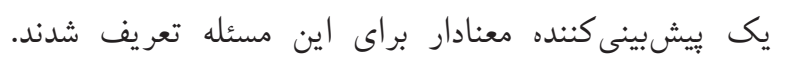

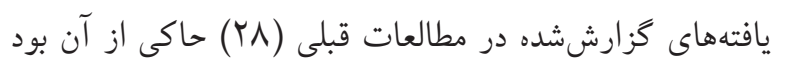

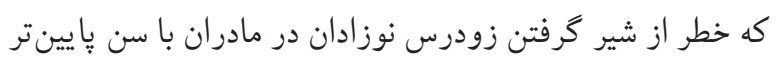
از · · سال، شش برابر بيشتر از ساير ين است. سطح تحصيلات

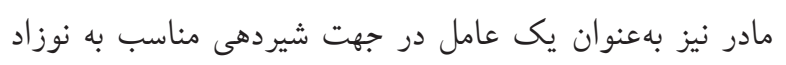

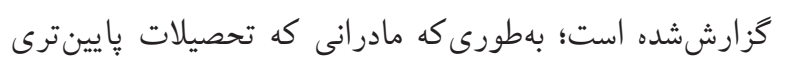

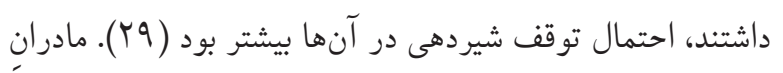

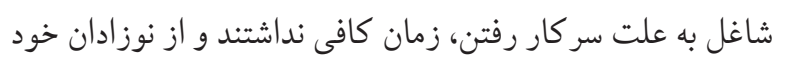

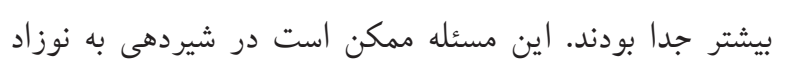

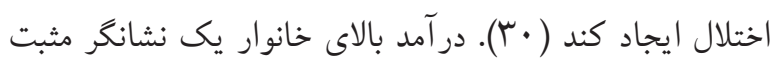
براى شيردهى است. در صورتى كه خانوارهاى درآمد مناسب دارند، بهتر است مادران سر كار نروند تا زمان كافى براى حضور

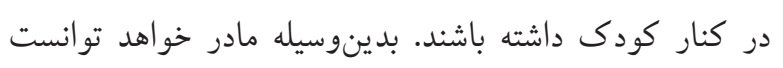

شرايطى را براى شيردهى مناسب به نوزاد خود فر اهم كند.

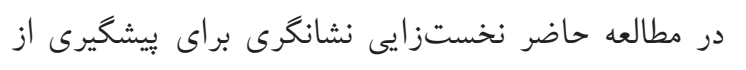

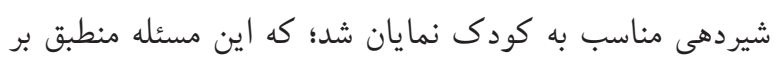
مطالعه انجام شده در كشور هند بود (YN). ممكن است است اين مسئله

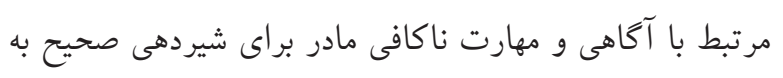

و ماه را گز ارش كردند. متغيرهاى شناختى مثل آكاهى از تأثيرات مفيد شيردهى، نكرش، هنجارهاى ذهنى، خودهو يتى و هنجارهاى

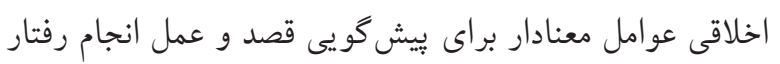

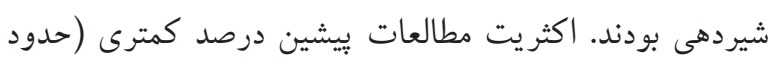

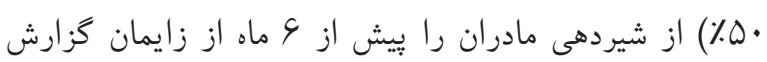

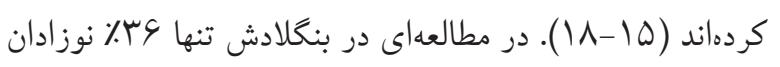
در 9 ماهه اول توسط مادرانشان شير داده شدند (9 (1)؛ كه مشابه كزارش مطالعات جنوب آسيا بود. در اين مطالعات ميزان شيردهى در ماههاى سوم، جهارم و ششم پِ ديس از زايمان به ترتيب

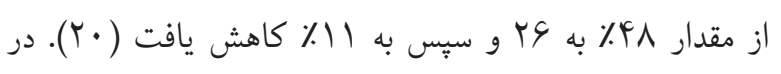

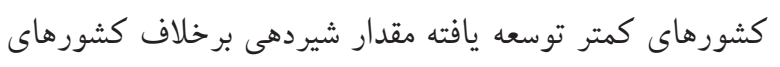

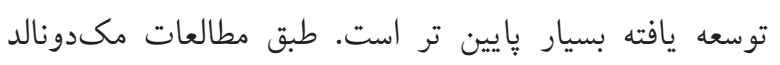

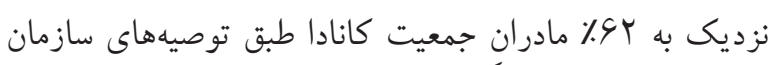
جهانى بهداشت رفتار شيردهى داشتند (Y) (Y). نيلسن و و همكاران

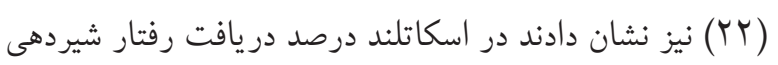

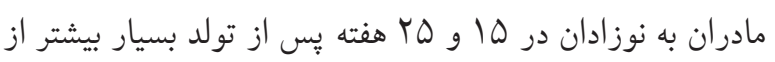
ميانگين ساير كشورهاى جهان بود.

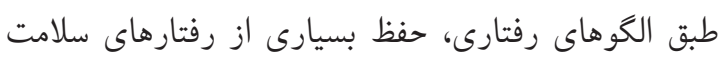

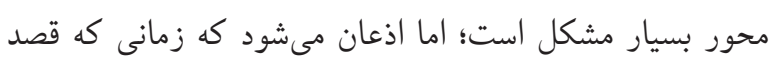
انجام رفتار ويزهاى قوى باشد، عمل به رفتار موردنظر بسيار

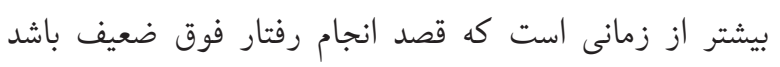

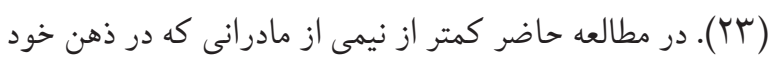

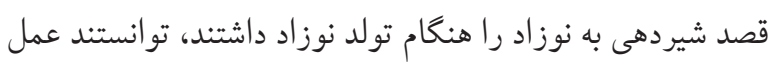

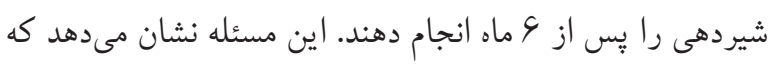
قصد حر كت به سمت رفتارى همجون شيردهى، عاملى بيشيش بينى

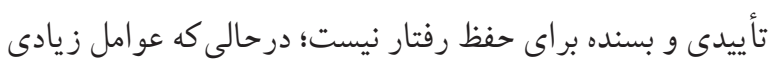

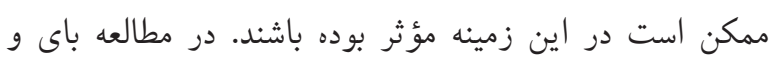

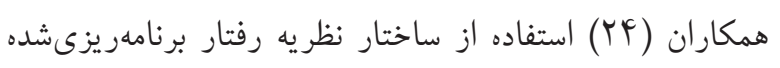
همجون نگرش، هنجار ذهنى و كنترل رفتارهاى دريافتى ارتباط

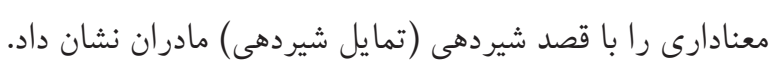
در مطالعه مشابه ديكر (YO) ساختار نظريه رفتار برنامهريزى (تشده، 
و درآمد خانوار مىتواند تأثيرات عمدهاى بر روى رفتار شيردهى

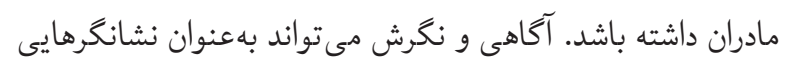
قوى در جهت بهبود رفتار شيردهى مادران تأثير بحذارد. شناخت صحيح اين متغيرها و توجه به آنها مى تواند بر موانع رفتار عدم شيردهى مادران غلبه نمايد و به بهبود ميزان شيردهى در مادران بهخصوص در مادران جوان و مادران در حال تحصيل و با درآمد جإيين منجر كردد.

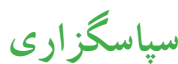

از مركز تحقيقات عوامل اجتماعى مؤثر بر سلامت و شوراى يُزوهشى دانشخاه علوم يزشكى قزوين به ياس حمايت از اين طرح تحقيقاتى قدردانى مى گردد.

\section{References}

1. Olds DL. Prenatal and infancy home visiting by nurses: From randomized trials to community replication. Prev Sci. 2002 Sep 1;3(3):153-72. http://dx.doi. org/10.1023/A:1019990432161

2. Hunt H. breastfeeding and society. Pediatric nursing.2006; 18(8): $240-246$

3. Shadzi Sh. Principles for reaching children's Health. Esfahan Kankash.1998; 100-102

4. Marshall JL, Godfrey M, Renfrew MJ: Being a good mother; managing breastfeeding and merging identities. Social ScienceMedicine.2007; 65(10):2147-2159

5. Kamer MS, Kakuma R. The optimal duration of exclusive breastfeeding: a systematic review. Adv Exp Med Biol.2004; (554): 63-77

6. WHO: The World Health Organizations Infant Feeding recommendation http://www.who.int/nut/

7. The World Health Organizations: Indicators for Assessing Infant and Young Child Feeding Practices Part 1 Definition. Washington DC [USA]: World Health Organization. Dept. of Child and Adolescent Health and Development; 2007

8. Adhikari M, Khanal V, et al. Factors associated with early initiation of breastfeeding among Nepalese mothers: further analysis of Nepal Demographic and Health Survey. 2011 International Breastfeeding Journal.2014; (9): 21-27.

9. Olang B, Heidarzadeh A, Strandvik B, Yngve A. Reasons given by mothers for discontinuing breastfeeding in Iran. International Breast Feeding Journal.2012; (7): 1-9.

10. National Integrated Monitoring and Evaluation Survey (IMES) of Family Health. Islamic Republic of Iran

Summer.2009; (1): 272-4

11. Hockenberry, Wilson k. Wong's nursing care of infant and children. 8th ed. Missouri: Mosby; 2007.p. 290-291

$$
\begin{aligned}
& \text { نوزاد باشد. همجنين ممكن است تصور غلط كه شيردهى اثر } \\
& \text { نامطلوب بر تناسباندام و بهبود يس از زايمان دارند، باعث } \\
& \text { اختلال شيردهى مادر به نوزاد شود. } \\
& \text { يكى از محدوديتهاى اين مطالعه انتخاب يك استان } \\
& \text { براى مطالعه بود؛ لذا نمىتوان نتايج را بر ساير استانها، به } \\
& \text { دليل تفاوتهاى فرهنگى و اقتصادى، تعميم داد. در اين مطالعه } \\
& \text { شيردادن توسط خود فرد گزارش شده بود؛ كه اين مسئله ممكن } \\
& \text { است باعث ايجاد مقدارى خطا گر دد. } \\
& \text { نتيجاه كيرى } \\
& \text { درنهايت مى توان اظهار داشت كه متغيرهايى مانند آكاهى و نگرش } \\
& \text { مادران و نيز متغيرهاى زمينهاى مانند تحصيلات، وضعيت اشتغال }
\end{aligned}
$$

12. Ziaee T, Qanbari A, HassanzadehRad A, Yazdani MA. The causes failure in breastfeeding in the first 6 month of life among children under 3 years Referred to health centers of Rasht city, IJOGI.2015; 15(18): 32-39.

13. Tehrani H, Majlessi F, Shojaeizadeh D, Sadeghi R, Kabootarkhani MH. Applying Socioecological Model to Improve Women's Physical Activity: A Randomized Control Trial. Iranian Red Crescent Medical Journal. 2016;18(2).

14. Defranc A, Van den Broucke S, Leroy R, Hoppenbrouwers $\mathrm{K}$. Measuring oral health behavior in Flemish health care workers: an application of the theory of planned behavior Community Dental Health.2008; 25(2): 107-1417-

15. Mgongo, M., et al., Prevalence and predictors of exclusive breastfeeding among women in Kilimanjaro region, Northern Tanzania: a population based cross-sectional study. International Breastfeeding journal.2013; 8(1): p. 12.

16. Queluz, M.C., et al., [Prevalence and determinants of exclusive breastfeeding in the city of Serrana, Sao Paulo, Brazil]. Rev Esc Enferm USP. 2012; 46(3): 537-43.

17. Noughabi, Z.S., et al., Prevalence and factors associated with exclusive breastfeeding at 6 months of life in Tehran: a population-based study. Eastern Mediterranean Health Journal.2014; 20(1): 24-32.

18. Olang, B., et al., Breastfeeding in Iran: prevalence, duration and current recommendations. International Breastfeeding journal 2009; 4: 8.

19. Joshi, P.C., et al., Prevalence of exclusive breastfeeding and associated factors among mothers in rural Bangladesh: a cross-sectional study. International Breastfeeding journal. 2014; 9 : 7.

20. Laisiriruangrai, P., et al., Prevalence of exclusive breastfeeding at 3, 4 and 6 months in Bangkok 
Metropolitan Administration Medical College and Vajira Hospital. Journal of Medical Association Of Thailand. 2008; 91(7): 962-7.

21. McDonald, S.D., et al., Prevalence and predictors of exclusive breastfeeding at hospital discharge. Journal of Obstetrics and Gynecology.2012; 119(6): 1171-9.

22. Nielsen, S.B., et al., Adequacy of milk intake during exclusive breastfeeding: a longitudinal study. Pediatrics. 2011; 128(4): 907-14.

23. VafaiNajar A, Masihabadi $M$, Moshki $M$, Ebrahimipour $\mathrm{H}$, Tehrani $\mathrm{H}$, Esmaeli $\mathrm{H}$, et al. Determining the Theory of Planned Behavior's Predictive Power on Adolescents' Dependence on Computer Games. Iranian Journal of Health Education and Health Promotion. 2015;2(4):303-11.

24. Bai, Y., S.M. Wunderlich, and A.D. Fly, Predicting intentions to continue exclusive breastfeeding for 6 months: a comparison among racial/ethnic groups. Maternal and Child Health Journal.2011; 15(8): 1257-64.

25. Bai Y, Middlestadt SE, Peng CY, Fly AD. Predictors of continuation of exclusive breastfeeding for the first six months of life. J Hum Lact. 2010 Feb 1;26(1):26-34. http:// jhl.sagepub.com/content/26/1/26.short

26. Hogg, M.A. and D. Abrams, Social identification: a social psychology of intergroup relations and group processes. 1988, London: Routledge.

27. Hamilton, K., et al., Predicting mothers' decisions to introduce complementary feeding at 6 months. An investigation using an extended theory of planned behaviour. Appetite. 2011; 56(3): 674-81.

28. Chudasama, R.K., P.C. Patel, and A.B. Kavishwar, Determinants of exclusive breastfeeding in South Gujarat region of India. J Clin Med Res. 2009; 1(2): 102-8.

29. do Nascimento, M.B., et al., Exclusive breastfeeding in southern Brazil: prevalence and associated factors. Breastfeed Med.2010; 5(2): 79-85.

30. Mascarenhas ML, Albernaz EP, Silva MB, Silveira RB. Prevalence of exclusive breastfeeding and its determiners in the first 3 months of life in the South of Brazil. J. Pediatr. (Rio J.). 2006 Aug;82(4):289-94. http://dx.doi. org/10.1590/S0021-75572006000500011 